\title{
LOSS OF DIFFERENTIATING NEMATOCYTES INDUCED BY REGENERATION AND WOUND HEALING IN HYDRA
}

\author{
TOSHITAKA FUJISAWA \\ National Institule of Genetics, Mishima, Shizuoka 411, Japan \\ AND CHARLES N. DAVID \\ Zoologisches Institut, Universität München, Luisenstr. 14, 8000 München 2, Federal \\ Republic of Germany
}

\begin{abstract}
S UMMARY
Cell death was observed in the nematocyte differentiation pathway in Hydra during head and foot regeneration. This death occurs throughout the regenerating piece, is transient in nature and is selective for committed stenotele and desmoneme precursors. Proliferating nematoblasts are unaffected. Cell death appears to be caused by release of a toxic factor rather than loss of a hormone required for differentiation, since regenerating pieces released a factor that inactivated differentiating nematocytes, and injured animals that had intact head and foot tissue also lost differentiating nematocytes. The inactivated nematocytes are removed by phagocytosis by epitheliomuscular cells.
\end{abstract}

\section{INTRODUCTION}

Cell death is commonly observed during development of various organisms. In some cases cell death is genetically programmed, as in certain cell lineages during nematode embryogenesis (Sulston \& Horvitz, 1977). In other cases cell death occurs in response to changes in cellular environment in the tissue, as in limb development (Saunders, 1966). Finally, cell death may be an important mechanism for regulating the rate of erythrocyte production, since the survival of intermediates (CFU-e) in the erythrocyte differentiation pathway appears to depend on the level of the hormone erythropoietin (Stephenson, Axelrad, MacLeod \& Shreeve, 1971). In this report we describe an example of cell death in the nematocyte differentiation pathway in Hydra. In this case death is caused by an unfavourable environment in the regenerating tissue and/or by phagocytosis of committed nematocyte precursors. As a result the rate of nematocyte differentiation is transiently reduced.

When pieces of tissue are isolated from the body column of $H y d r a$, they respond by regenerating head and foot tissue at the appropriate ends. During this process a number of changes occur in the cell composition of the piece of tissue. In particular, the tissue at the cut ends is transformed from the gastric tissue, which contains large numbers of interstitial stem cells and differentiating nematocytes, to head or foot tissue, which lacks these cell types and has instead large numbers of nerve cells (Bode et al. 1973). Some of these changes occur slowly and appear to involve changes in stem cell proliferation and stem cell commitment to nerve and nematocyte differentiation. 
However, there is also evidence that nematoblasts and nematocytes are inactivated by the regeneration process (Yaross \& Bode, 1978). In this report we describe a related phenomenon: the selective loss of differentiating stenoteles and desmonemes that is induced in regenerating pieces following removal of head and/or foot tissue. Unlike the changes at the cut surface, this loss (1) occurs throughout the regenerating piece, (2) is transient in nature and (3) selective for committed stenotele and desmoneme precursors. Proliferating nematoblasts, which are uncommitted to a specific type of nematocyte differentiation, are unaffected. Although the selective inactivation of differentiating nematocytes could be due to loss of a hormone required for differentiation, the present results appear to favour a mechanism involving the release of a toxic factor, which inactivates these cells over a period of several days during regeneration. Our results suggest that inactivated cells are removed from tissue by phagocytosis by ectodermal epithelial cells.

MATERIALS AND METHODS

Hydra

Hydra attenuata was cultured at $19^{\circ} \mathrm{C}$ in a solution containing $1 \mathrm{~mm}-\mathrm{CaCl}_{2}, 1 \mathrm{~mm}-\mathrm{NaHCO}_{3}$ and $0.01 \mathrm{~mm}$-EDTA. Animals were fed daily with freshly hatched Artemia salinas nauplii and washed $6 \mathrm{~h}$ later.

Recently detached buds were used for all experiments. Regenerating animals were fed daily by inserting Artemia into the gastric cavity with a micropipette until the ability to feed themselves was restored.

\section{Cell type analysis}

Cell types were analysed by maceration using phase-contrast optics (David, 1973). Stem cells occur in macerations as single large interstitial cells and in nests of two cells. We refer to them as $1 \mathrm{~s}+2 \mathrm{~s}$. We refer to nests of four and eight proliferating nematoblasts as $4 \mathrm{~s}$ and $8 \mathrm{~s}$, respectively. We refer to nests of postmitotic cells in which nematocyst capsules are differentiating as 'differentiating nematocytes'.

\section{Identification of phagocytosed cells in epithelial cells}

To identify and score phagocytosed cells or cell fragments in epithelial cells, maceration preparations were stained by the Feulgen method with Fast Green counterstain (Pearse, 1960). Phagocytosed cells occurred in phagocytic vacuoles in epithelial cells. Their condensed chromatin was intensely stained by the Feulgen (red) method and the cytoplasm exhibited a pale green colour by Fast Green counterstain.

\section{RESULTS}

\section{Nematocyte differentiation during head and foot regeneration}

The head and foot of Hydra were amputated at time zero and both regenerating tips were removed $12 \mathrm{~h}$ later. Samples of 10 Hydra were macerated every day during regeneration and the number of each cell type was scored. As shown in Fig. A $_{A-D}$, the numbers of epithelial cells, $1 \mathrm{~s}+2 \mathrm{~s}$ and nematoblasts ( $4 \mathrm{~s}$ and $8 \mathrm{~s}$ ) increased exponentially during regeneration. (The animals were fed daily during the course of regeneration.) In contrast to this increase, the numbers of differentiating stenoteles and desmonemes decreased sharply between days 4 and 6 and between days 3 and 5 
of regeneration, respectively, and then began to recover towards normal levels (Fig. $1 \mathrm{E}, \mathrm{F})$. In control animals all cell types increased exponentially during the course of the experiment (Fig. 1, closed symbols).
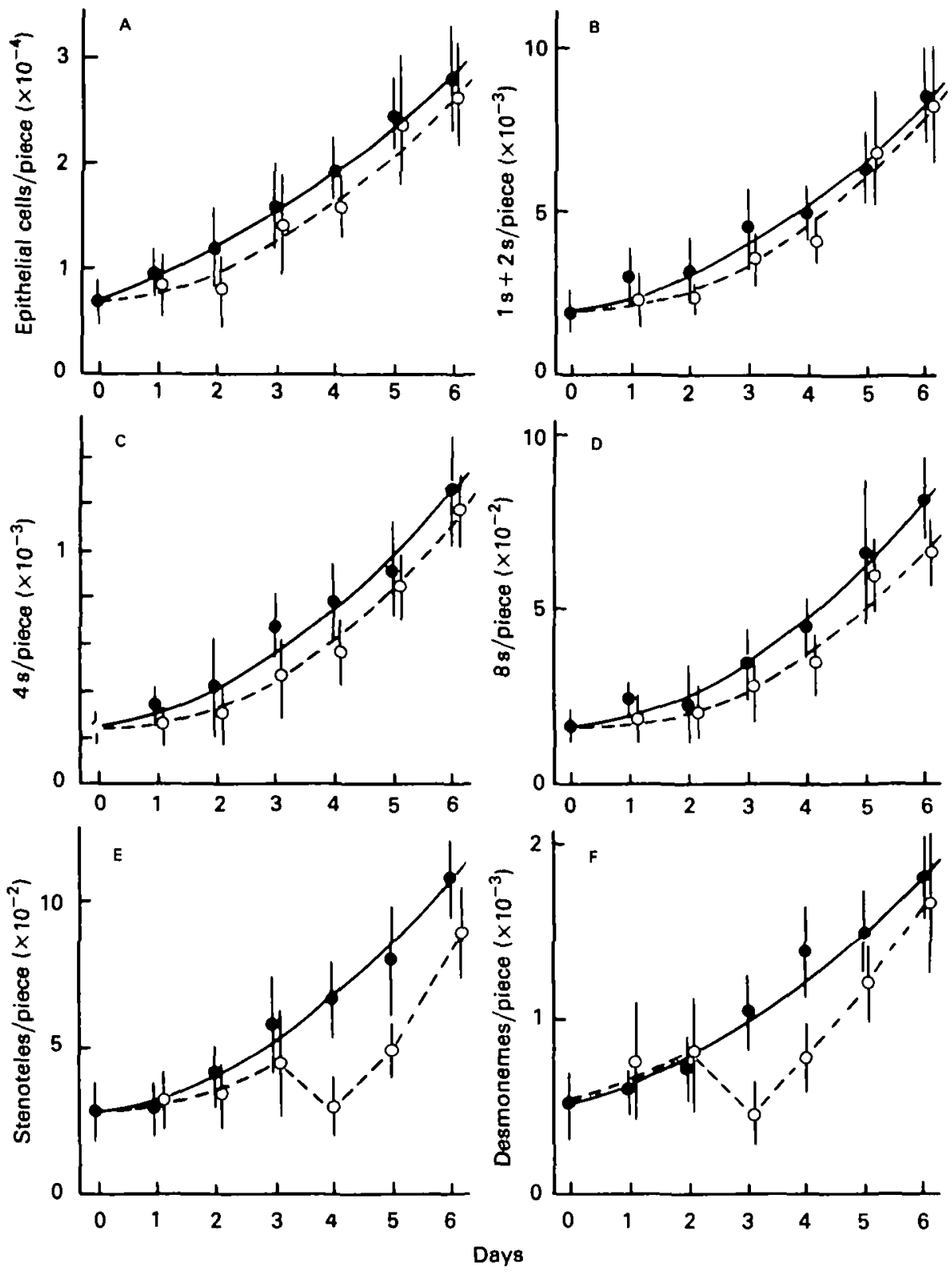

Fig. 1. Changes in the numbers of various cell types during head and foot regeneration. The head and foot were amputated at time 0 and both regenerating tips were removed $12 \mathrm{~h}$ later. The head and foot regions were removed from intact control animals immediately before maceration to make the number of epithelial cells comparable to that of regenerating pieces. A. Epithelial cells;, $1 \mathrm{~s}+2 \mathrm{~s} ; \mathrm{c}, 4 \mathrm{~s} ; \mathrm{D}, 8 \mathrm{~s} ; \mathrm{E}$, stenoteles; F, desmonemes. Control animals; ( $\bigcirc$. . . O) regenerating animals. 
Since the numbers of precursor cells ( $4 \mathrm{~s}$ and $8 \mathrm{~s}$ ) are not affected by the treatment, the loss of differentiating stenoteles and desmonemes must occur at a stage during capsule differentiation after the terminal cell cycle. This stage lasts about 2 days for desmoneme differentiation and 3 days for stenotele differentiation (David \& Gierer, 1974). Thus, if we assume that the effect of regeneration begins at the time of cutting, the results in Fig. 1E, F suggest that cells early in the differentiation pathway are severely affected, while cells further along the differentiation pathway at the time of cutting are resistant to the treatment.

Several other aspects of the results in Fig. 1E, F deserve mention. (1) The great majority of differentiating stenoteles and desmonemes are located along the body column a long way from the cut surfaces where head and foot regeneration occurs. The 'inactivating' effect of regeneration on stenotele and desmoneme differentiation is therefore long-range. It could be due to a toxic factor released as a result of regeneration or the loss of a 'hormone' required for nematocyte differentiation and produced normally by head and foot tissues. Results described below favour the first hypothesis. (2) The inactivating effect of regeneration persists for several days after removal of the head and foot. Fig. $1 \mathrm{E}$ shows that the number of stenoteles did not recover to the control level even on day 6 of regeneration. The number of desmonemes started to recover on day 4 and reached the control level on day 6 (Fig. 1F). Since the numbers of $4 \mathrm{~s}$ and $8 \mathrm{~s}$ are unaffected and since the differentiation time for desmonemes and stenoteles is 2 and 3 days, respectively (David \& Gierer, 1974), these results indicate that stenotele and desmoneme precursors are still being inactivated 1 to 3 days after the onset of regeneration. (3) The inactivating effect of regeneration acts on differentiating nematocyte precursors but does not affect proliferating nematoblasts (i.e. $4 \mathrm{~s}$ and $8 \mathrm{~s})(\mathrm{Fig} .1 \mathrm{C}, \mathrm{D})$. Previous results have shown that the transition from proliferation to differentiation is accompanied by commitment to a particular type of capsule differentiation (Fujisawa \& David, 1981, 1982). Thus, the differential sensitivity of proliferating and differentiating precursors may be related to the qualitative change in these cells from uncommitted to committed.

\section{Removal of differentiating nematoblasts by phagocytosis by epithelial cells}

The results above show that differentiating nematocytes are severely affected by regeneration. In this section we examine the fate of these inactivated cells. Since earlier work had shown that epithelial cells (both epitheliomuscular cells and digestive cells) can phagocytose interstitial cells and nematoblasts under certain circumstances (Campbell, 1976), we looked for evidence of phagocytosed nematocytes in regenerating animals. The head and foot of Hydra were amputated at $0 \mathrm{~h}$, and $12 \mathrm{~h}$ later both regenerating tips were removed. At different times thereafter groups of 10 animals

Fig. 2. Epitheliomuscular cells containing phagocytic vacuoles. The cells were stained by the Feulgen method with Fast Green counterstain. $\times 1400$. A. Epitheliomuscular cell containing no phagocytic vacuole. B, C, D. Epitheliomuscular cells containing phagocytosed cells. The chromatin (dark spots) and the cytoplasm (grey) of the engulfed cells is condensed (B). The condensed nucleus disintegrates into several chromatin granules $(c, D)$. 


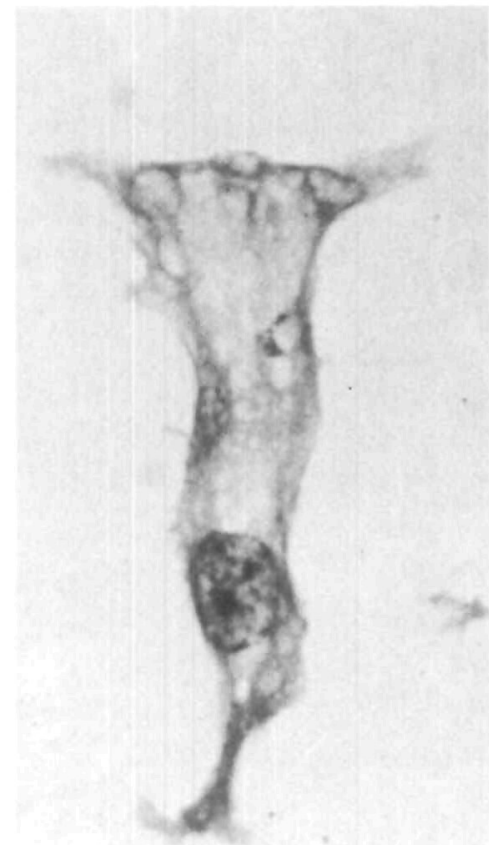

$2 \mathrm{~A}$

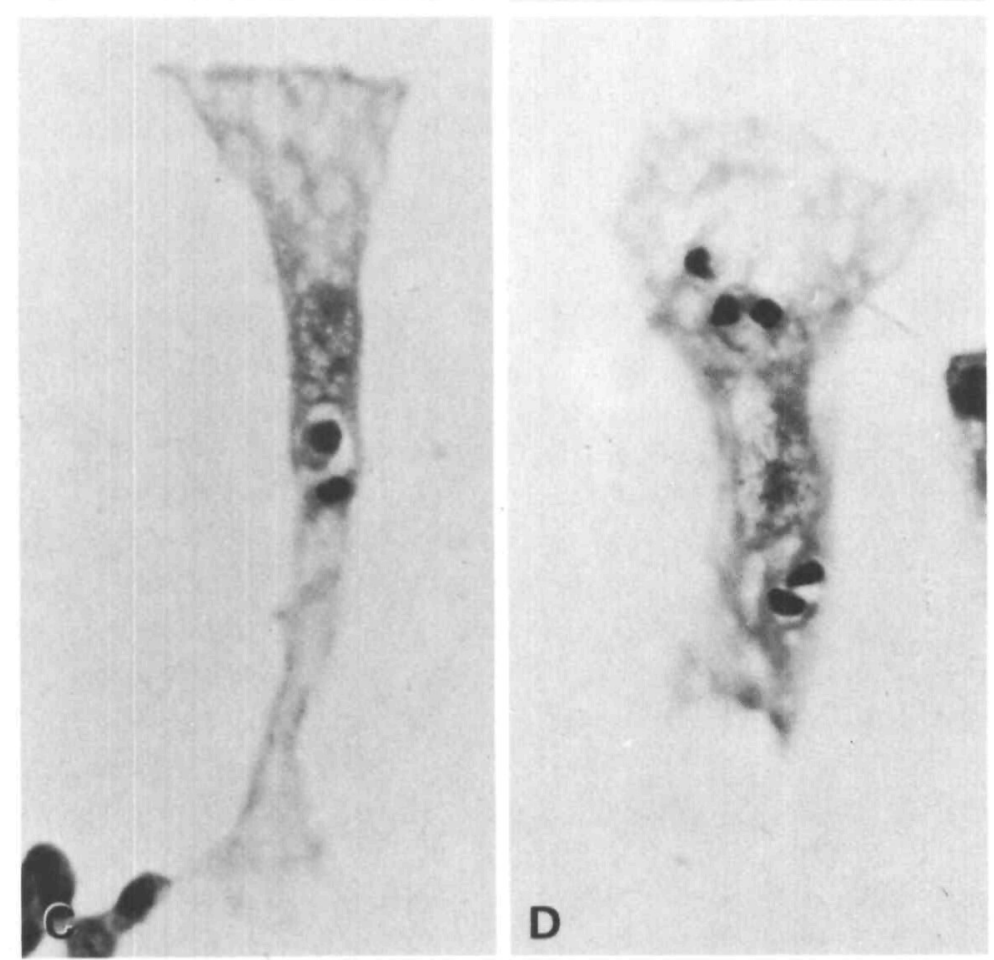

Fig.2 
were macerated. Macerated preparations were stained by the Feulgen method with Fast Green counterstain to observe nematocytes phagocytosed by epithelial cells. It was possible to distinguish between cytoplasm (green) and nucleus (red) by this method. As shown in Fig. 2 differentiating nematocytes and cell fragments were found in what appear to be phagocytic vacuoles in epitheliomuscular cells. Fig. 2B shows an epitheliomuscular cell that contains two differentiating nematocytes in large vacuoles in the cytoplasm (see the difference in Fig. $2 \mathrm{~A}$, which shows the same cell type containing no phagocytosed cell). These engulfed cells have already started the pycnotic condensation of chromatin and have reduced nuclear volumes. Thus, they are intensively stained by the Feulgen method. In other cells cytoplasm is barely visible or invisible and the nucleus becomes disintegrated into several chromatin granules (Fig. 2c, D). Since their morphological changes are characteristic of the multiphased process of phagocytosis (Walters \& Papadimitriou, 1978), we interpret such cells as phagocytosed cells included in phagocytic vacuoles of epitheliomuscular cells. Digestive cells contained very few phagocytosed cells (see below). Since almost none of the phagocytosed cells had a distinguishable capsule in its cytoplasm, cells early in the differentiation pathway were selectively phagocytosed.

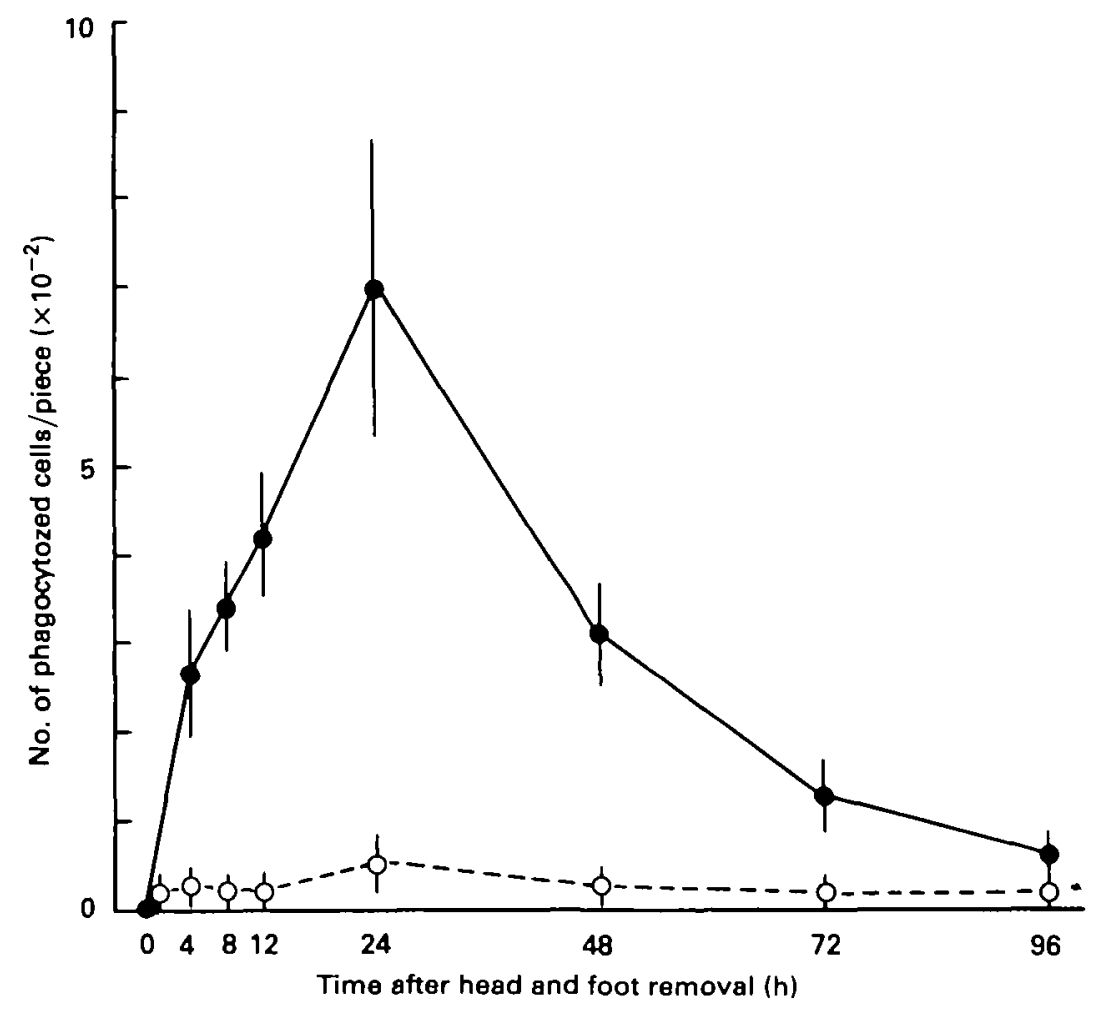

Fig. 3. Change in the number of cells phagocytosed by epithelial cells (epitheliomuscular cells + digestive cells) during regeneration. The head and font of an intact animal were amputated at time 0 , and $12 \mathrm{~h}$ later both regenerating tips were removed again. For further details see the text. (O) Cells phagocytosed by epitheliomuscular cells; (O) cells phagocytosed by digestive cells. 
Table 1. Comparison of the number of phagocytosed nematocytes in epithelial cells with the number of nematocyte precursors lost on each day

\begin{tabular}{ccc}
\hline Day & $\begin{array}{c}\text { No. of phagocytosed nematocytes in } \\
\text { epithelial cells* }\end{array}$ & $\begin{array}{c}\text { Estimated no. of lost nematocyte } \\
\text { precursors } \dagger\end{array}$ \\
\hline 0 & 40 & 120 \\
1 & 680 & 1050 \\
2 & 290 & 710 \\
3 & 160 & 450
\end{tabular}

- Data from Fig. 3.

† The number of nematocyte precursors lost on each day was estimated from Fig. 1E,F using the capsule differentiation times of 2 days for desmonemes and 3 days for stenoteles (David \& Gierer, 1974).

To measure the extent of phagocytosis by epithelial cells we scored the number of epitheliomuscular cells and digestive cells containing phagocytosed cells. Fig. 3 shows the estimated total number of phagocytosed cells per regenerating piece. More than $90 \%$ of phagocytosed cells occurred in epitheliomuscular cells, indicating that digestive cells did not contribute to any significant extent to the removal of differentiating nematocytes. Phagocytosed cells started to appear in vacuoles of epitheliomuscular cells as early as $4 \mathrm{~h}$ after the head and foot amputation. Their number increased rapidly reaching a maximum at $24 \mathrm{~h}$ and gradually decreased during the next 3 days. Since this timing of phagocytosis seemed to be correlated with the loss of nematocyte precursors (Fig. 1D, E), we compared the number of phagocytosed cells with the estimated number of nematocyte precursors lost on each day (Table 1). The comparison shows (1) the parallel change in the numbers of phagocytosed cells and nematocyte precursors lost during the first 3 days of regeneration, and (2) the two- to threefold difference between the number of phagocytosed cells and the estimated loss of nematocyte precursors. These results suggest that the duration of the phagocytosis process is at least several hours and that phagocytosis can start even 2 days after the final amputation. However, a quantitative comparison is not possible at the moment because we do not know to what extent phagocytosis is responsible for the loss of differentiating nematocytes (mechanisms other than phagocytosis may be involved) and thus we do not know the exact duration time of the phagocytosis process.

\section{A factor released during regeneration causes the loss of nematocyte precursors}

Groups of 10 freshly detached buds were selected from the mass culture and incubated in $10 \mathrm{ml}$ of culture solution containing 50 regenerating animals. The regenerating animals were obtained by removing the head and foot at time zero and by removing the regenerating tips again at $12 \mathrm{~h}$. After $24 \mathrm{~h}$ of incubation the intact animals were washed and transferred to $10 \mathrm{ml}$ of fresh culture solution containing no regenerating animal, and then incubated further. Groups of 10 animals were macerated every day for 5 days and the numbers of various cell types were scored. 

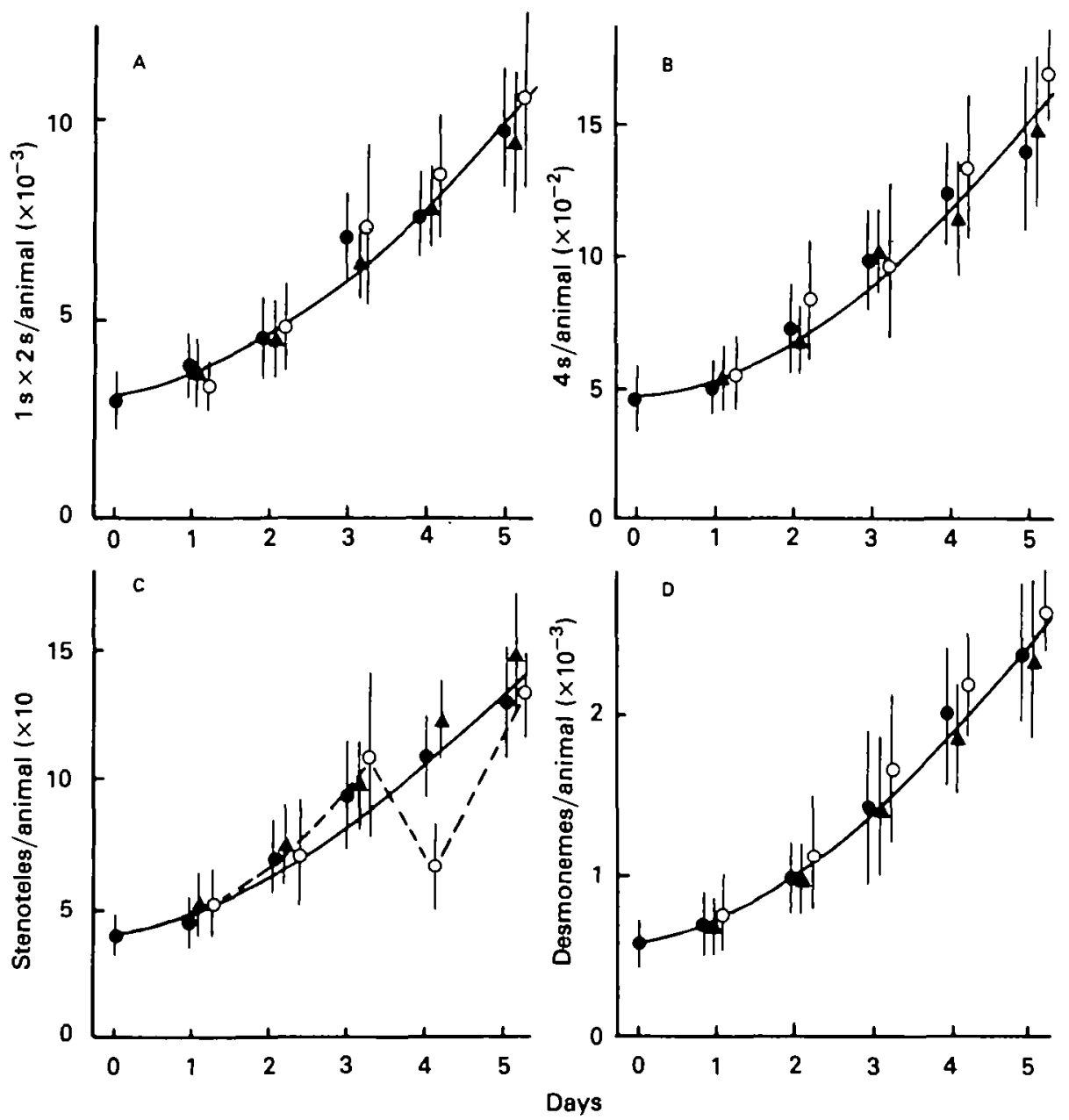

Fig. 4. Effect of a factor released by regenerating animals on nematocyte differentiation. Ten intact animals were incubated with 50 head and foot regenerating anımals in $10 \mathrm{ml}$ of culture solution for $24 \mathrm{~h}$. A. $1 \mathrm{~s}+2 \mathrm{~s}$; B, $4 \mathrm{~s}$; C, stenoteles; D, desmonemes. (O) Control animals without incubation; $(\Delta)$ control animals picked randomly from 60 intact animals;

(O) animals incubated with regenerating pieces.

Two control experiments were performed: (1) groups of 10 intact animals were cultured in $10 \mathrm{ml}$ of culture solution, macerated every day for 5 days and scored for the number of each cell type. (2) Sixty intact animals were cultured in $10 \mathrm{ml}$ of culture solution for 24.h. After this period 10 animals were picked randomly and cultured for 4 more days. Groups of 10 animals were macerated and scored as described above. The results are shown in Fig. 4. In all cases the numbers of $1 s+2 s, 4 s$ and desmonemes increased with a doubling time of about 3 days (Fig. 4A, B, D). The epithelial cells increased at similar rates (data not shown). In contrast, in intact animals incubated with regenerating pieces the number of stenoteles decreased about $40 \%$ on day 4 , compared to control animals (Fig. 4c). Although the effect is restricted to stenotele 

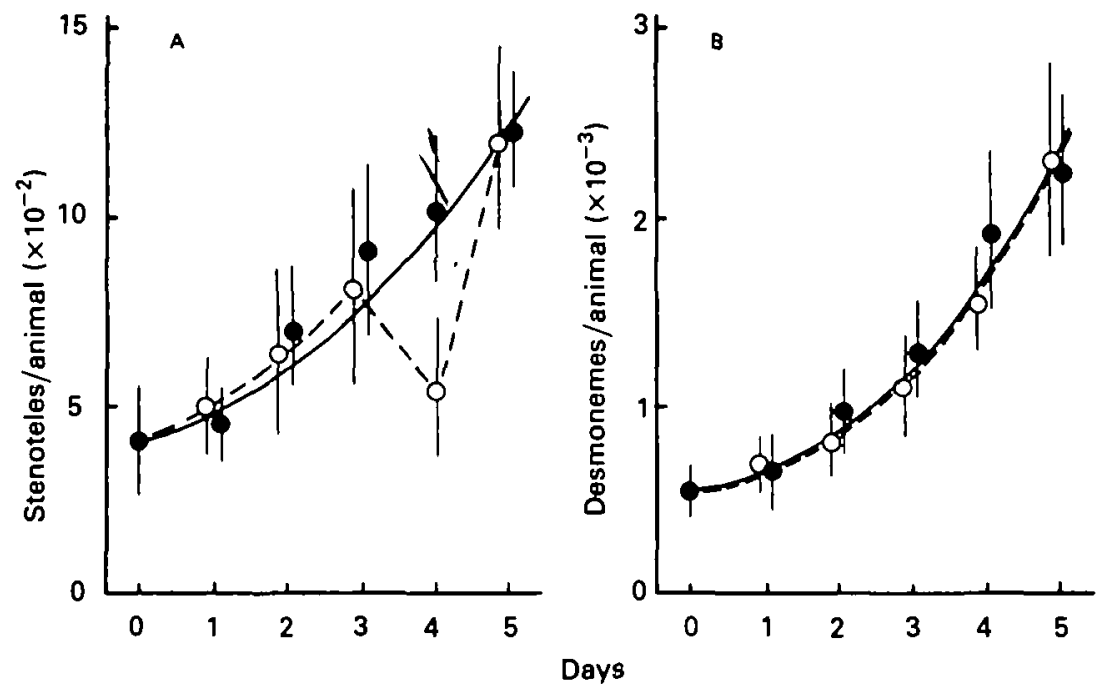

Fig. 5. Effect of crude extract on nematocyte differentiation. Ten intact animals were incubated with crude extract for $24 \mathrm{~h}$. A. Stenoteles; B, desmonemes. (O) Untreated control animals; $(O)$ animals treated with crude extract.

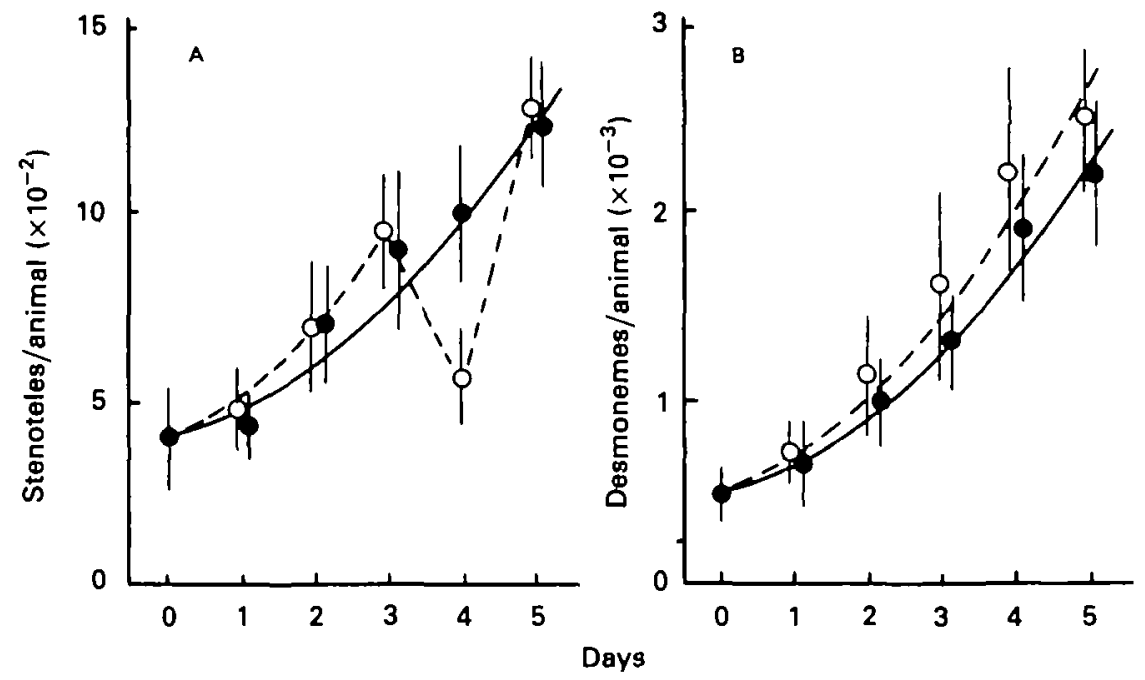

Fig. 6. Effect of injury on nematocyte differentration. Intact animals were injured by making three transverse cuts into the body column (see the text). A. Stenoteles; B, desmonemes. (O) Uninjured control animals; $(O)$ injured animals.

differentiation, the results support the idea that a factor that inactivates nematocyte differentiation is released into the culture solution by regenerating animals.

Similar inhibitory effects were found using crude extract of Hydra tissue. Hydra were picked randomly from the mass culture and sonicated to obtain crude extract (the final concentration of extract in culture solution had an 0.D.280 $=0.25$, which 

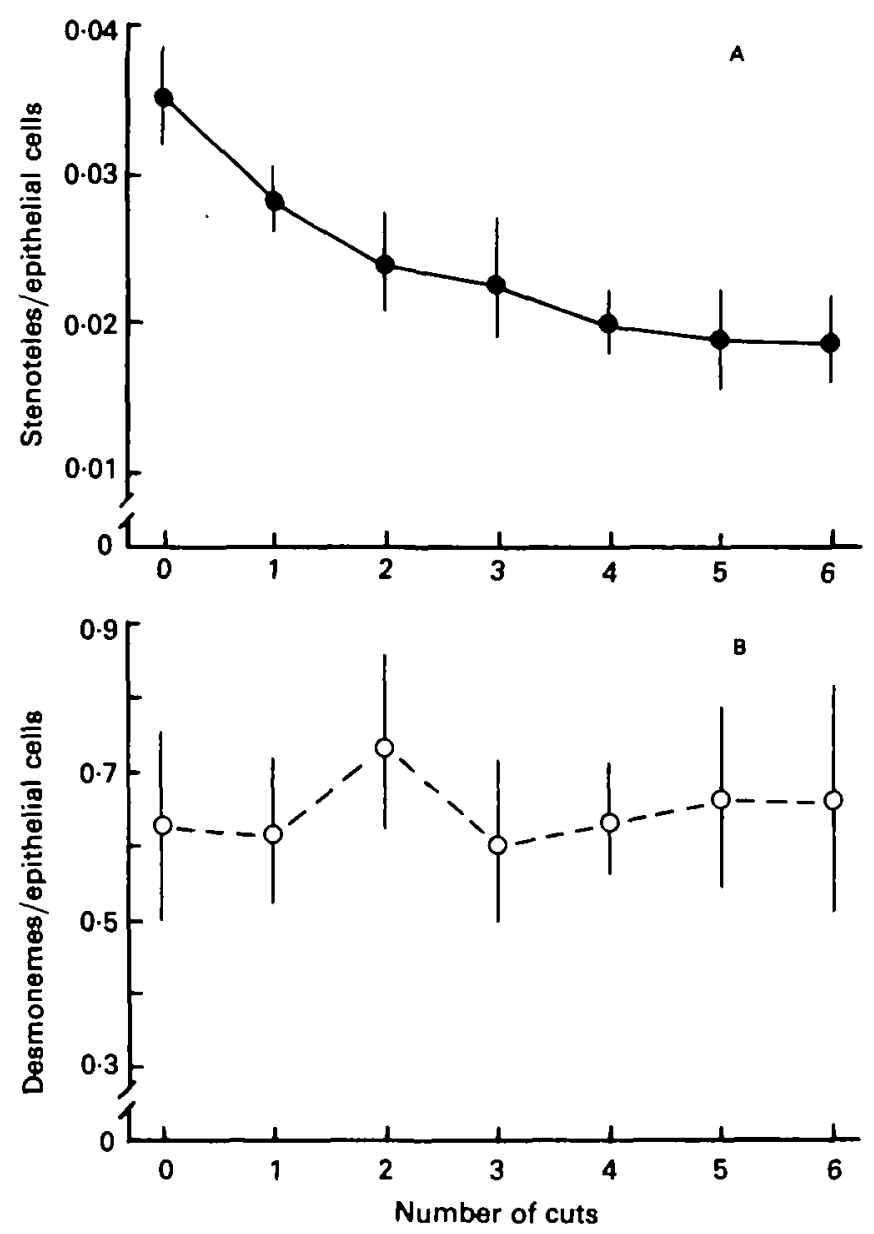

Fig. 7. Dosage effects of injury on nematocyte differentiation. Intact animals were injured by making up to six transverse cuts in the body column at $0 \mathrm{~h}$ and again at $12 \mathrm{~h}$. The ordinate shows the ratio of the number of stenoteles or desmonemes to that of epithelial cells. A. Stenoteles; B, desmonemes.

corresponds to about 1 hydra $/ \mathrm{ml}$ ). Groups of 10 animals were treated with extract for $24 \mathrm{~h}$. The culture solution was replaced with fresh extract once after $12 \mathrm{~h}$ of incubation. After $24 \mathrm{~h}$ the animals were washed and transferred to fresh solution containing no extract. Thereafter, animals were macerated every day for 5 days. The results are shown in Fig. 5. In animals treated with crude extract the number of stenoteles decreased about $50 \%$ on day 4 , compared to the control value (Fig. $5 \mathrm{~A}$ ). In contrast, the number of desmonemes was not affected by the treatment (Fig. 5B) nor were the numbers of epithelial cells, $1 s+2 s, 4 s$ and $8 s$ in the treated animals (data not shown).

\section{Effects of injury on nematocyte differentiation}

The previous experiments suggest that a factor that inactivates differentiating stenoteles is released from regenerating tissue and is present in crude extracts (Figs 4,5 ). This finding is not consistent with the hypothesis that differentiating stenoteles 
and desmonemes decrease because removal of the head and/or foot removed the source of a required hormone. We have done the following experiments to test further whether or not the presence of the head and foot is required for nematocyte differentiation. Intact animals were injured by making three transverse cuts in the body column: the first cut in the upper gastric region, the second in the mid-gastric region and the third in the lower gastric region. The cuts were made at $0 \mathrm{~h}$ and again at $12 \mathrm{~h}$. Thereafter, groups of 10 animals were macerated and the numbers of the various cell types were scored. In both injured animals and uninjured control animals the numbers of epithelial cells, $1 s+2 s, 4 s$ and $8 s$ increased exponentially during 5 days after the injury (data not shown). The number of desmonemes also increased exponentially (Fig. 6B). However, the number of stenoteles decreased on day 4 (Fig. 6A). The timing of this decrease was very similar to that observed in animals incubated with regenerating pieces (Fig. $4 \mathrm{C}$ ) or treated with crude extract (Fig. 5A). In other experiments in which three cuts were made in the upper gastric region stenotele differentiation was also inactivated, indicating that the effect of cutting is long-range since stenoteles are differentiated primarily in the proximal half of the body column (data not shown).

The reason for the quantitative difference between the results with injuries and regeneration is not known, but might be explained by the assumption that regeneration is an extreme case of injury. To examine this possibility animals were extensively injured by introducing up to six cuts into the body column at $0 \mathrm{~h}$ and again at $12 \mathrm{~h}$. The numbers of differentiating stenoteles and desmonemes were scored on days 4 and 3 , respectively. The results in Fig. $7 \mathrm{~A}$ indicate a correlation between the 'dosage' of cuts and the decrease in stenotele number. However, even multiple cuts made on the body column failed to lower the desmoneme number (Fig. 78).

\section{DISCUSSION}

The present experiments have demonstrated a selective decrease in the numbers of stenotele and desmoneme nematocytes induced by removal of the head and foot from Hydra; nests of proliferating nematoblasts ( $4 \mathrm{~s}$ and $8 \mathrm{~s}$ ) are not affected by the treatment (Fig. 1). The decrease in stenotele and desmoneme numbers started 3 to 4 days after removal of the head and foot, suggesting that precursors in the early stages of differentiation are preferentially affected by the treatment. These cells are committed to stenotele or desmoneme differentiation whereas proliferating nematoblast nests are not (Fujisawa \& David, 1981). Hence, the effect of removal of the head and foot appears to be only on recently committed cells.

Observations related to ours have been made by Yaross \& Bode (1978). However, there are several significant differences between their findings and ours. (1) Yaross \& Bode observed nematocyte loss only in the regenerating tip, whereas our observations indicate that the effect occurs throughout the regenerating piece. In particular, it is clear that the effect of removal of the head and foot is long-range since cells far from the site of cutting are inactivated. (2) Yaross \& Bode reported that regeneration caused a decrease in both proliferating nematoblasts (uncommitted) and differentiating 
nematocytes (committed). In contrast, our results indicate that proliferating nematoblasts are unaffected. One reason for this difference may be that cells in regenerating tips and cells in the body column react differently. However, it is also possible that feeding the regenerating pieces in our experiments contributed to the survival of proliferating nematoblasts. (3) In our experiments the effect of removal of head and foot is transient, lasting only about 3 days after cutting, whereas Yaross \& Bode observed a permanent inhibition of nematocyte differentiation. This is certainly due to the difference between the regenerating tip and the body column of the regenerate.

There are two likely hypothesis to explain the loss of stenotele and desmoneme precursors: (1) release of a toxic substance by wounding and/or regeneration of hydra tissue; and (2) loss of a hormone produced by head and foot tissue and required for nematocyte differentiation. The present results appear to favour the first hypothesis, since regenerating pieces release a factor that can cause the loss of differentiating nematocytes in intact Hydra (Fig. 4), and since wounding of tissue causes a loss of stenotele precursors despite the presence of the head and foot tissue (Fig. 6).

Although the reason for the inactivation of differentiating nematocytes during regeneration is not known, it may be a means by which regenerating pieces 'feed themselves' at the expense of cells that are not immediately required for regeneration. Such an explanation is also supported by the observation that these inactivated cells are phagocytosed by epitheliomuscular cells (Fig. 3) and thus their energy content is made available to the host tissue.

This research was carried out in the Department of Molecular Biology at the Albert Einstein College of Medicine. It was supported by grants from the NIH (GM11301), the NSF (80-22675) and the DFG (Da 163/1-1) to C.N.D. and T.F. was the recipient of a fellowship from the Japanese Ministry of Education.

\section{REFERENCES}

Bode, H. R., Berking, S., David, C. N., Gierer, A., Schaller, H. \& Trenkner, H. (1973). Quantitative analysis of cell types during growth and morphogenesis. Wilhelm Roux Arch. EntwMech. Org. 171, 269-285.

Campbell, R. D. (1976). Elimination of hydra interstitial and nerve cells by means of colchicine. J. Cell Sci. 21, 1-13.

David, C. N. (1973). A quantitative method for maceration of Hydra tissue. Wilhelm Roux Arch. EntwMech. Ong. 171, 259-268.

David, C. N. \& Gierer, A. (1974). Cell cycle kinetics and development of Hydra attenuata. III. Nerve and nematocyte differentiation. F. Cell Sci. 16, 359-375.

Fujisawa, T. \& David, C. N. (1981). Commitment during nematocyte differentiation in $H y d r a$. 7. Cell Sci. 48, 207-222.

Fujisawa, T. \& David, C. N. (1982). Commitment during stenotele differentiation in Hydra is localized near the $S / G 2$ boundary in the terminal cell cycle. Devl Biol. 93, 226-230.

Pearse, A. G. E. (1960). Histochemistry, Theoretical and Applied. Boston: Little Brown \& Co. Saunders, J. W. (1966). Death in embryonic systems. Science, N.Y. 154, 604-612.

Stephenson, J. R., Axelrad, A. A., Mcleod, D. L. \& Shreeve, M. M. (1971). Induction of colonies of hemoglobin-synthesizing cells by erythropoietin in vitro. Proc. natn. Acad. Sci. U.S.A. $68,1542-1546$. 
Sulston, J. E. \& Horvitz, H. R. (1977). Post-embryonic cell lineages of the nematode, Caenorhabditis elegans. Devl Biol. 56, 110-156.

Walters, M. N. J. \& Papadimitriou, J. M. (1978). Phagocytosis: a new review. Crit. Rev. Toxicol. 5, 377-405.

Yaross, M. S. \& Bode, H. R. (1978). Regulation of interstitial cell differentiation in Hydra attenuata. V. Inability of regenerating head to support nematocyte differentiation. $\mathcal{F}$. Cell Sci. 34, 39-52.

(Received 21 December 1983-Accepted 11 January 1984) 
